\title{
OS STAKEHOLDERS E SUA INFLUÊNCIA EM UMA REDE DE EMPRESA NA DESTINAÇÃO TURÍSTICA DE URUBICI/SC. ${ }^{1}$
}

\section{THE STAKEHOLDERS AND ITS INFLUENCE IN A NET OF COMPANY IN THE TOURIST DESTINATION OF URUBICI/SC.}

\author{
Ariani Raquel Neckel ${ }^{2}$ \\ Fabiela Fatima Andrighi ${ }^{3}$ \\ Vamil Emil Hoffmann ${ }^{4}$
}

RESUMO: O estudo dos stakeholders e sua influência nas redes de empresas são temas contemporâneos para academia. Apesar de sua importância, observa-se a escassez de trabalhos voltados especificamente a esta temática e seu uso como meio descritivo para assimilar a dinâmica social de relações existentes (HALL, 2001). Este artigo analisa os stakeholders e suas influências nas empresas de hospedagem de Urubici/SC. Para alcançar o objetivo proposto, utilizou-se o método quantitativo de caráter exploratório-descritivo, com utilização de questionário. A amostra foi composta por nove pousadas associadas à Pouserra, que é a instituição que representa as empresas no destino turístico. Como resultado, constata-se que os stakeholders que mais influenciam as pousadas pertencentes à rede de empresas são os clientes e em segundo lugar está a família, o que de certa forma repete resultados anteriores, e abre a discussão sobre a importância das instituições locais em termos de estratégia para cada empresa.

Palavras Chaves: rede de empresas, stakeholders, destinação turística, estratégias, instituições.

ABSTRACT: The study of the stakeholders and their influence on business nets are contemporary themes for academy. In spite of their importance, few studies specifically related to such subject have been carried out, as well as its use as a descriptive tool to assimilate the social dynamics of occurring relationships (HALL, 2001). This article aims to identify the stakeholders and their influences on lodging businesses in Urubici/SC. In order to reach the intended objective, a quantitative method of exploratory-descriptive character has been used, by applying a questionnaire form. The sample was composed by nine lodges associated to Pouserra, institution that represents local tourism businesses. As a conclusion, this study has shown that the stakeholders with greater influence on the lodges belonging to the analyzed business net are the clients and, secondly, the family. In a way, this repeats previous results and opens discussion on how strategically important local institutions are to tourism businesses.

Key words: networks, stakeholders, tourism, strategies and institutions.

\footnotetext{
${ }^{1}$ Artigo Recebido em 22.09.2008 . Revisado por pares em 02.01.2009 . Recomendado em 04.03.2009 por Denise Del Pra Netto Machado (editora). Publicado em 22.04.2009. Organização Responsável pelo periódico: Universidade regional de Blumenau - FURB - www.furb.br/rn

${ }^{2}$ Universidade do Vale do Itajaí - UNIVALI - arianineckel@hotmail.com

${ }^{3}$ Universidade do Vale do Itajaí - UNIVALI - fabiela@dalmir.com.br

${ }^{4}$ Universidade do Vale do Itajaí - UNIVALI - ehoffmann@univali.br
} 


\section{INTRODUÇÃO}

A busca por estratégias que incrementem a competitividade tem-se constituído em objetivo constante de empresas, como fator crítico para a ascensão em um ambiente de concorrência global (AMATO NETO, 2005). Uma alternativa dessas estratégias, que já vem sendo adotada desde as últimas décadas, parece ser a formação de desenhos organizacionais para além do paradigma hierarquia e mercado (POWELL, 1990; RING; VAN DE VEN, 1992): a formação de redes de empresas. As redes de empresas representam um novo modelo organizacional que vem ao encontro dessas modificações entre as ações adotadas para aumentar a competitividade de setores empresariais que motivam, valorizam e reconhecem que a cooperação entre as organizações leva a desempenho e qualidade superiores.

$\mathrm{O}$ estudo das redes de empresas reúne significados de interação, conexão e interconexão (GARCIA, 2001). Conforme Andion (2003), as redes são processos de interação entre atores, os quais estão ligados diretamente com âmbito local de desenvolvimento. São formadas por entes com características semelhantes e através de sua sinergia, colaboram e cooperam para a obtenção de objetivos comuns (ENDRES, 2003). As redes de empresas, apesar de serem um modelo organizacional estudado inicialmente na administração de empresas, também existem relacionadas ao turismo. No turismo, segundo Tremblay (1998), as redes de empresas realizam a ligação entre as potencialidades individuais encontradas nos destinos turísticos e tornam a concorrência uma competição sadia, tendo como referência a busca em atingir a vantagem competitiva no âmbito coletivo.

Contudo, é importante para a rede de empresas ter habilidade de ponderar a participação de seus atores na tomada de decisões. Cabe lembrar que a organização em rede é diversificada e complexa, havendo a necessidade de considerar a relevância dos stakeholders e suas contribuições. Stoner e Freeman (1985) definem os stakeholders como os grupos ou indivíduos afetados direta ou indiretamente pela busca dos objetivos por parte de uma organização. Toda empresa tem seus próprios stakeholders, que podem ser identificados a partir de uma análise realizada no mercado em que atuam, bem como o grau de intensidade desta influência (FREEMAN; REED, 1983).

Corroborando, Sabino et al. (2005) argumentam que os stakeholders possuem grande potencial de influência no ambiente e na estrutura das organizações, devendo esta se preocupar também com todos os atores que podem influenciar na sua tomada de uma decisão. Aquele trabalho desenvolveu a temática da influência dos stakeholders nos atores que compõe uma rede de empresa, pois segundo Silva et al. (2005), os stakeholders são partes do processo de construção e administração do futuro da rede, por serem a ligação entre as organizações. Os stakeholders possuem grande potencial de influência no ambiente e na estrutura das organizações, suprindo-as com importantes contribuições e necessitando de atenção e conhecimento sobre quem são e quais são suas expectativas.

Considerando o contexto apresentado, este trabalho analisa os stakeholders e suas influências nas empresas de hospedagem de Urubici/SC. A escolha pelos atores pertencentes à rede de empresas Pouserra foi baseada por sua aglomeração geográfica e localização na destinação turística de Urubici/SC, que possui um potencial econômico, social e principalmente turístico - com atrativos diferenciados (SANTUR, 2006).

O trabalho apresenta além desta introdução, os conceitos encontrados na literatura de rede de empresa e stakeholders. Em seguida desenvolve a influência dos stakeholders na rede de empresa e como é possível determiná-la. Detalha a metodologia que envolveu o trabalho, descrevendo um breve histórico sobre a Pouserra e posteriormente são detalhados os resultados da pesquisa realizada na rede de empresa na destinação turística de Urubici/SC e as considerações finais. 


\section{REDES DE EMPRESAS}

Um novo modelo organizacional representado por rede de empresas vem sendo adotado desde os anos oitenta do século passado para aumentar a competitividade de empresas, setores e regiões, que valoriza e reconhece a cooperação entre as organizações e leva a desempenho e qualidade superiores (RIBAULT, MARTINET, LEBIDOIS, 1995; CASAROTTO FILHO; PIRES, 1999; AMATO NETO, 2000; FLEURY; FLEURY, 2001). Em busca de explicação da competitividade e chances de competir em melhores condições com concorrentes mais estruturados e treinados, as empresas buscam se organizar em rede com outras empresas do mesmo setor e também de setores diferentes. Este tipo de comportamento ocorre no turismo, pois a maioria dos negócios do setor no Brasil são pequenas e microempresas (PME), com até 19 pessoas empregadas e geram $60 \%$ dos empregos (IBGE, 2007). A constituição de redes de empresas é a alternativa competitiva que essas PME possuem para conseguir escala e conseqüente redução de custos.

Muito se discute em relação à conceituação de redes de empresas, que buscam representar o fim do isolacionismo das organizações e suscitam mudanças, de estrutura organizacional, no estilo de gestão e na forma de organização das relações entre as empresas (VILLELA, 2005). Para Thorelli (1986), uma rede de empresas é o que há de intermediário entre uma simples empresa e o mercado. Corroborando, Miles e Snow (1986) destacam que é a combinação única de estratégias, estrutura e do processo de gestão de cada empresa. Redes de empresas são consideradas por Jarillo (1998), como acordos de longo prazo com objetivos comuns entre empresas independentes, que possibilitam a obtenção de uma vantagem competitiva.

Porter (1999) utiliza o termo cluster para definir rede de empresa concentrada geograficamente, com o objetivo de obterem vantagem competitiva. Cândido e Abreu (2000) consideram rede de empresa o relacionamento entre empresas que por motivos de limitações de tamanho e estrutura, buscam conquistar coletivamente condições de sobrevivência e de desenvolvimento. Segundo aqueles autores, as redes possuem uma estrutura organizacional flexível e com inovações, tendo como objetivo a competitividade dos atores participantes.

Rede de empresa é definida por Amato Neto (2000) como sendo um agrupamento, com objetivo principal de fortalecer as atividades com participação de seus atores cooperando em aspectos técnicos, administrativos, sem que haja necessariamente, laços financeiros entre eles, com possibilidades de prazo indeterminado e aberto a novos participantes. As redes de empresas são compreendidas por Silva et al. (2005) como organizações empresariais, pouco rígidas, que geram competitividade, tendo o enfoque no longo prazo. Para fins deste trabalho, as redes podem ser definidas como acordos de longo prazo, formais ou não, entre distintos atores, cujo escopo se relacione à geração de vantagens competitivas sustentáveis.

A relatividade nos papéis dos atores organizacionais; interação; interdependência das partes; complementaridade; especialização das atividades das empresas; competitividade são algumas das características evidenciadas por Hoffmann (2002) para as redes de empresas. Ainda segundo aquele autor, no que se refere às vantagens proporcionadas pela formação das redes de empresas, são citadas desde melhoria da produtividade, redução de custos, economia de recursos, acesso a novos mercados, novas tecnologias, mão-de-obra e fornecedores, aumento do poder de barganha em compras e comercialização, trocas de experiências, maior acesso a informação, melhoria da reputação do setor, até o maior acesso a crédito, a instituições e programas governamentais.

No turismo, as motivações que levam ao desenvolvimento das redes de empresas são relacionadas à necessidade de articular medidas e instrumentos horizontais de promoção da 
eficiência e do bom desempenho das atividades produtivas com ações seletivas que concentrem esforços e a verticalização, o que pode proporcionar vantagens competitivas (MILES; SNOW, 1986). No turismo os atores possuem certa interdependência típica para o desenvolvimento das atividades, (SELIN; BEASON, 1991). Observa-se que o setor turístico está estruturado geograficamente em agrupamentos (PAVLOVICH, 2003), o que possibilita ter como resultado um produto turístico mais competitivo, que não seria possível realizar isoladamente. Entretanto, mesmo com as possíveis vantagens geradas pela formação e participação nas redes de empresas, o gerenciamento das mesmas torna-se um desafio, pois podem ser complexos administrativamente e ao desenvolverem relacionamentos mais abertos, podem gerar o oportunismo. Para Mazzali e Costa (1997), a organização em redes está vinculada ao amadurecimento da interdependência entre as empresas, constituindo-se em forma particular de coordenação das decisões de recursos e de atividades. Ou seja, a rede é uma solução para a problemática da coordenação dos agentes em uma determinada atividade econômica. Lagemann (2004) ressalta que é importante identificar quais os fatores que podem afetar o desempenho das redes, o que permite aos participantes de redes maior conhecimento sobre essa alternativa estratégica.

Considerando o desenvolvimento da rede como um processo, Chisholm (1996) destaca que seu início está na fase do reconhecimento do problema, passando pelo planejamento do desenvolvimento da rede, a visão do futuro, a convocação e participação dos stakeholders e, finalizando, com a organização para a ação. Este trabalho vai se concentrar na fase que envolve os stakeholders, especificamente na sua influência nos atores pertencentes à rede de empresa e conseqüentemente também influenciam as decisões da rede em estudo.

\section{STAKEHOLDERS E A INFLUÊNCIA NA REDE DE EMPRESAS}

Duas definições de stakeholder são propostas por Freeman e Reed (1983): um sentido amplo e um sentido restrito. No sentido amplo, stakeholder podem influenciar a execução dos projetos de uma organização ou serem influenciados por estes, são identificáveis e podem ser grupo ou indivíduo. Para o sentido restrito stakeholder, também pode ser grupo ou indivíduo identificável, mas a organização é dependente para a sua contínua sobrevivência.

Consumidores, acionistas, credores, fornecedores, parceiros, governos, comunidade, empregados, entre outros, são exemplos de stakeholders, considerando a definição de Freeman (1984, p. 48): "stakeholders são grupos ou indivíduos que afetam ou são afetados pela realização dos objetivos organizacionais". Este é um dos primeiros conceitos, considerados abrangentes, pois possibilita discussão por diversos autores de maneiras diferentes, e apoiadas por uma miríade de argumentos e evidências contraditórias (DONALDSON; PRESTON, 1995). Os autores Donaldson e Preston (1995), ao estudarem o tema apresentaram o conceito de stakeholders em três âmbitos:

- descritivo/empírica: abrange o gerenciamento da organização, buscando compreender as características e comportamentos dos gestores e suas estratégias de gestão.

- instrumental: identifica a influência dos stakeholders no desempenho da organização através do estudo da relação entre os stakeholders e os objetivos da empresa.

- normativa: interpreta a missão da organização, sua sistemática, cultura e filosofia de atuação e de gestão.

Para Bowditch e Buono (1992), stakeholders podem ser considerados atores identificáveis, dos quais a organização depende para sobreviver: acionistas, funcionários, clientes, fornecedores e entidades governamentais e sugerem que o comportamento estratégico é afetado por diversos stakeholders situados no ambiente, bem como, as 
estratégias da organização devem buscar satisfazê-los da melhor maneira possível. Mitchell et al. (1997) apresentam uma proposta de classificação para os stakeholders, fundamentada em três valores: poder, legitimidade e urgência. Ou seja, 1) o poder do stakeholder de influenciar a organização; 2) a legitimidade do relacionamento do stakeholder com a organização; e 3) a urgência no atendimento do stakeholder para a organização. Aqueles autores mencionam que o objetivo em classificar os stakeholders está relacionado com a possibilidade de identificar quais grupos de stakeholders a organização deve considerar para o direcionamento de suas estratégias e metas. Esta classificação identifica ainda, que se o ator não possuir pelo menos um destes valores, não recebe atenção da organização e desta maneira não são stakeholders.

Para o desenvolvimento deste trabalho os stakeholder são compreendidos como qualquer ator que apresente uma relação, interesses ou expectativas sobre a organização (SAVAGE et al., 1991; DONALDSON; PRESTON, 1995) e utilizando a premissa dos estudos de Frooman (1999) que está baseada em três dimensões para o estudo dos stakeholders, 1) quem são eles e quais suas características, 2) quais são seus interesses e prioridades individuais e 3) quais estratégias utilizam para influenciar a empresa.

A importância dos stakeholders está fundamentada no grau de contribuição para competitividade da organização (ATKINSON et al., 1997) e no poder político que exercem nas organizações, que necessitam de conhecimento para decisões mais politizadas (FREEMAN; REED, 1983). Estudos sobre o desenvolvimento das estratégias e como as organizações determinam as decisões abordam os stakeholders como influenciadores deste processo (FROOMAN, 1999): Pinto e Oliveira (2003) destacam o potencial de influência dos stakeholders na estrutura das organizações e a busca pela satisfação de seus interesses e expectativas através de incentivos da organização; Karpouzas e Santos (2005) expõem que o poder privado, o poder público e o terceiro setor são influenciados pelos stakeholders, que auxiliam na conquista dos objetivos.

No turismo, alguns estudos realizados nacional e internacionalmente apontam que os stakeholders podem ter grande importância no processo decisório de empresas ou mesmo de um conjunto delas. O trabalho de Hatton (2004) identificou uma redefinição nos papeis entre os atores envolvidos na comercialização de bilhetes aéreos. O autor destacou que as empresas de aviação passaram a exercer uma estratégia que poderia chamada de retenção direta, usando a classificação de Frooman (1999), na medida em que passaram a reduzir as comissões pagas aos agentes, e também a vender bilhetes diretamente ao consumidor final. Isso forçou os agentes a se especializarem, alterando sua estratégia mais voltada para o atendimento e consultoria que para a representação (TOMELIN, 2001). O trabalho realizado por Sabino et al. (2005) procurou identificar os stakeholders e verificar também seu grau de importância. Pode-se considerar que aquele trabalho foi precursor desse, em termos de escopo de pesquisa. Os resultados daquele estudo apontam que os clientes e os sócios são os stakeholders mais importantes para o grupo de pousadas estudado, sendo que enquanto os sócios são interdependentes com as pousadas, as pousadas dependem dos clientes e por eles são influenciadas nas suas tomadas de decisão.

Ressalta-se que as redes de empresas possuem um relacionamento diversificado, tornando a identificação da emersão ou formalização de estratégias uma tarefa mais complexa (KARPOUZAS; SANTOS, 2005). Segundo Silva et al. (2005), os stakeholders são partes do processo de construção e administração do futuro da rede, por serem a ligação entre as organizações. Aqueles autores argumentam que a fase final do processo de desenvolvimento da rede de empresas é quando a organização está direcionada para a ação, compreendendo as formas distintas de analisar as mudanças e as organizações. Parece que é nesta fase que as mudanças organizacionais acontecem efetivamente, demonstrando o êxito no 
desenvolvimento de uma rede de empresas. Consideram o processo de desenvolvimento da rede e na qualidade do relacionamento existente entre os seus componentes como fatores para este sucesso.

\section{METODOLOGIA}

Para o desenvolvimento desta pesquisa utilizou-se uma abordagem quantitativa, visto que possibilita a precisão de resultados e evita distorções na análise e interpretação de dados, o que possibilita uma margem de segurança (RICHARDSON, 1999), com uma abordagem de pesquisa descritiva.

Os atores em análise são as pousadas associadas à Associação de Pousadas e Hotéis de Urubici - Pouserra, que no período da coleta de dados - maio de 2006 - compreendiam 09 estabelecimentos. A escolha pelos atores pertencentes à Pouserra foi baseada por sua aglomeração geográfica e localização da rede de empresas na destinação turística de Urubici/SC, que possui um potencial econômico, social e principalmente turístico - com atrativos diferenciados (SANTUR, 2006). A Pouserra foi fundada no ano de 2001, com o objetivo de integrar o poder público e privado para o desenvolvimento das atividades turísticas em Urubici. No mês de maio de 2006, contava com 09 pousadas associadas, que se reuniam uma vez por mês para discutir e planejar estratégias para os associados e para a destinação, confirmando o conceito sobre rede de empresas citado por Andion (2003) e Endres (2003). Considerando o número de atores fonte deste estudo, foi realizado um censo, ou seja, a enumeração completa de uma população (MALHOTRA, 2001).

Com a intenção de atingir o objetivo proposto para este estudo, os dados foram coletados através de um questionário pré-elaborado por Hoffmann (2003) e adaptado pelos pesquisadores, com 23 perguntas abertas e fechadas. O questionário foi baseado nas percepções e atitudes dos pesquisados, utilizando-se a escala contínua por intensidade, para as questões fechadas, pois conforme Hayes (2001, p.41), "a confiabilidade das escalas é muito importante quando são estudadas as relações entre as variáveis". A escala contínua por intensidade utilizada foi de freqüência de 1 a 5 ; o número 1(um) representa a menor intensidade (nunca/não) e o 5 (cinco) a maior intensidade (sempre/sim).

A distribuição e o recolhimento dos questionários foram feitos pelos pesquisadores através de contatos diretos com os gestores das pousadas. O preenchimento se deu no próprio local de trabalho dos participantes. $O$ tratamento dos dados se deu por medidas de frequência.

\section{DESENVOLVIMENTO}

Os resultados da pesquisa apresentam primeiro uma análise das questões relacionadas diretamente à estrutura organizacional da pousadas como fundação, forma de gestão, número de colaboradores, entre outros. Em seguida, são apresentados os dados referentes aos clientes, origem, faixa etária, renda familiar e a motivação em relação à escolha. Na seqüência relaciona-se a atuação do empreendimento quanto ao mercado, sua relação com os concorrentes, clientes e fornecedores. E finalmente, apresenta-se a avaliação dos grupos que afetam ou são afetados pela empresa e a dependência existente entre os atores e a organização.

Como o turismo é ainda uma atividade recente para esta destinação, a organização das atividades turísticas e a aplicação como fonte de renda vem se desenvolvendo há menos de 05 anos. De certa forma isso indica que o turismo é uma atividade ainda recente no país, pois em outro estudo realizado por Curtis (2008), sobre as destinações turísticas de Gramado e Canela apontou que a maioria dos meios de hospedagem daquelas cidades tinha menos de 10 anos, sendo que cerca de $35 \%$ delas tinha menos de cinco anos. Nas ousadas de Urubici, 
apenas uma das respondentes iniciou a atividade no ano de 1999 e as demais possuem de três a quatro anos de atividade. Dos noves questionários, setes foram feitos com os proprietários, apenas duas pousadas possuem o cargo de gerente.

Em relação à formação dos entrevistados, cinco possuem o ensino médio, dois o ensino fundamental e dois o superior, nenhum dos entrevistados com ensino superior é formado na área da gestão, onde estão inseridos os cursos de administração, hotelaria e turismo.

A gestão familiar é a que predomina, o que explica o baixo número de funcionários auxiliando diretamente na empresa. Conforme apontado pelo IBGE (2007), uma das características do setor turístico no Brasil é sua formação por empresas pequenas e micro. Entre as pousadas respondentes apenas três possuem três funcionários, outras três possuem dois funcionários, uma possui apenas um funcionário e duas não possuem nenhum funcionário. Uma pousada é administrada por profissional, sendo que cinco das pousadas surgiram com a necessidade de uma nova atividade comercial, três com a indicação de amigos e apenas uma comentou que decidiu transformar sua casa em uma pousada na busca de uma nova oportunidade profissional. Quanto à motivação para o desenvolvimento da nova atividade, é possível observar a presença do stakeholders "amigos" influenciando, conforme definição de Freeman (1948, p.48) e diferentemente do apresentado no trabalho de Sabino et al. (2005), onde os resultados indicam os clientes, além dos sócios, como influenciadores no surgimento das pousadas.

A maioria dos clientes são oriundos do estado de São Paulo e do próprio estado de Santa Catarina. Foram citados turistas do estado do Paraná e também de outros países, mas este último não foi registrado. Em relação à faixa etária, $80 \%$ destes clientes estão entre 26 a 40 anos, $20 \%$ estão entre 41 a 55 anos. A Tabela 01 demonstra que a maioria dos turistas são casais sem filhos em nenhuma entrevista foi citada a vinda de solteiros. A predominância de casais e nesse faixa etária também foi observada por Sabino et al. (2005), o que pode significar que esse tipo de hospedagem é preferida por esse tipo de turista. No caso de Urubici, esse perfil também parece indicar que a destinação se firma mais como turismo de "Lazer", explicado pelo tipo de atrativo com várias cachoeiras, passeios a cavalo, caminhadas, e a gastronomia de frio.

Tabela 01 - Tipo de Clientes nas pousadas de Urubici.

\begin{tabular}{c|c|c|c|c}
\hline Tipo de clientes & \multicolumn{2}{|c|}{ Casais com filhos } & \multicolumn{2}{c}{ Casais sem filho } \\
\hline \multirow{2}{*}{$\mathrm{N}$} & $\%$ & $\mathrm{~N}$ & $\%$ \\
\cline { 2 - 5 } & 2 & $18 \%$ & 7 & $82 \%$ \\
\hline
\end{tabular}

Fonte: elaborado pelos autores

Como os empreendimentos são pequenos e não são informatizados, $50 \%$ dos entrevistados não souberam responder qual a renda da família dos turistas que visitam a cidade, dos que responderam 10\% acreditam que a renda está em torno de R\$: $1.000,00$ a $2.000,00,30 \%$ acreditam que esteja em torno de: $\mathrm{R} \$: 2.001,00$ a $\mathrm{R} \$: 3.000,00$ e os $10 \%$ restante: $\mathrm{R} \$$ : $3.001,00$ a $\mathrm{R} \$ 5.000,00$. Como a maioria das pousadas respondentes está localizada no centro da cidade, $50 \%$ responderam que o aspecto que leva os clientes a escolher seu empreendimento é a localização, os demais responderam que seria o atendimento. Se de fato é o atendimento que faz os clientes voltarem, a busca por sua melhoria pode ser uma influência desse stakeholder. Cabe salientar que no estudo de Sabino 
et al. (2005) igualmente os clientes apareceram como stakeholders importantes para as pousadas de Bombinhas.

Uma das questões consideradas importantes para analisar os stakeholders e a influência é a visualização das estratégias da empresa com relação ao momento atual e ao futuro e se estas consideram a influência dos stakeholders. Das empresas pesquisadas, 10\% têm como meta conquistar novos mercados, através da abertura de filias, outros $10 \%$ esperam abrir novas empresas que não esteja relacionado aos meios de hospedagem, os $80 \%$ restantes pretendem permanecer atuando no setor hoteleiro. Isso parece indicar um tipo de consenso em termos de objetivos estratégicos, e que como é comum ao maior grupo de empresas pesquisas, pode estar havendo uma influência mútua, entre os membros da rede. Isto é, nesse aspecto os membros da rede parecem ser stakeholders internos importantes para a rede. Em um âmbito instrumental (DONALDSON; PRESTON, 1995), poderia ser identificada a relação entre os stakeholders e os objetivos da empresa.

Outra questão foi saber qual a característica que a empresa considera ser a mais importante em relação ao mercado que atua. Dos entrevistados, $40 \%$ responderam que se preocupam em ter um padrão de qualidade específico de atendimento, considerando a lealdade do cliente o mais importante, os $60 \%$ restantes disseram que o mais importante é comprar os produtos à vista de seus fornecedores com o objetivo de redução de custo. Apenas $10 \%$ afirmaram que a empresa se importa os concorrentes, sendo que $90 \%$ dizem ser parceiros de outras pousadas. Quanto a este último resultado, pode-se perceber que talvez exista a interdependência entre eles, tal como foi destacado por Selin e Beason (1991) e contrariando o trabalho de Sabino et al. (2005), o que chama a atenção pois, naquele estudo, igualmente, as pousadas pesquisadas eram afiliadas à associação local.

Como o turismo é uma atividade que se característica pela prestação de serviços e que deve ser planejado de maneira que atenda o turista com qualidade, sabe-se que a influência causada pelos stakeholders deve ser levada em consideração no momento da criação de estratégias e principalmente deve-se analisar a expectativa e o interesse desses atores diante da organização. A Tabela 02 apresenta a maneira como a empresa toma suas decisões, em termos de pessoas envolvidas.

Tabela 02 - Tomada de decisão nas pousadas de Urubici

\begin{tabular}{|l|c|c|}
\hline \multicolumn{1}{|c|}{ Pessoas envolvidas na tomada de decisão } & \multicolumn{2}{c|}{ Quantidade de Pousadas } \\
\cline { 2 - 3 } & $\mathbf{N}$ & $\mathbf{5}$ \\
\hline A participação mais intensa é do(s) proprietário(s). & 5 & $55 \%$ \\
\hline Todos participam, dando sugestões e propondo soluções. & 4 & $45 \%$ \\
\hline $\begin{array}{l}\text { Algumas pessoas na empresa decidem periodicamente, e outro grupo } \\
\text { põe em prática o que foi decidido. }\end{array}$ & 0 & $0 \%$ \\
\hline Outras quais: & 0 & $0 \%$ \\
\hline
\end{tabular}

Fonte: elaborado pelos autores

É possível constatar que não são apenas os proprietários da organização que influenciam nas decisões da empresa, mas que em aproximadamente a metade dos casos, todos podem participar. É possível verificar na afirmação de Pinto e Oliveira (2003), que os stakeholders têm poder de influência na estrutura das organizações. De certa forma isso é corroborado pelos resultados da Tabela 4 que exprime os funcionários causam alta influência na decisão, na maioria das entrevistas., com relação à dependência, os respondentes apontaram para a interdependência entre funcionários e as pousadas. Os estudos de Freeman (1984); Savage et al. (1991); Bowditch e Buono (1992); e Donaldson e Preston (1995) já haviam apontado os funcionários (ou empregados) como stakeholders a serem analisados, em 
função de sua capacidade de influenciar a operação da empresa. Os resultados desse trabalho, em certa medida, confirmam sua importância.

O stakeholder que mais influencia na tomada de decisão é o cliente, pois todos os entrevistados colocaram que os fundamentos de suas ações são em função do bem estar dos turistas. Esta evidência também foi apresentada no estudo de Sabino et al. (2005) ao estudarem a importância dos stakeholders na tomada de decisão das pousadas de Bombinhas/SC. A família também possui alta influência, já que está intimamente ligada com o empreendimento e conseqüentemente observa-se que os entrevistados indicam que a empresa depende deste stakeholder, conforme Tabela 4. A Tabela 03 trata da influência dos stakeholders, sendo possível visualizar também que os concorrentes, fornecedores, bancos, governo municipal, governo estadual, associação e universidades/faculdades da região são os stakeholders percebidos como de menor intensidade de influências nos entrevistados. Precisa haver um indicativo que a rede formada pelas empresas não se abriu a participação de outros atores organizacionais naturalmente presentes nas aglomerações turísticas, como no caso da destinação de Urubici. Considerando as palavras de Cândido e Abreu (2000), que indicam que o objetivo das redes é a busca pela competitividade dos atores participantes, não haveria possibilidade de se incluir outros atores organizacionais como membros, pois os governos em si não vão buscar sua competitividade ao fazer parte das redes, e sim a manutenção dos empregos que a competitividade das empresas pode trazer. Essa pouca importância pode refletir negativamente no futuro da destinação e da própria rede, pois nos processos de planejamento turístico, o governo local quando não é o catalisador do processo, ao menos toma parte desse processo (RICHINS, 2000).

Tabela 03 - Relação dos Stakeholders nas pousadas de Urubici

\begin{tabular}{|l|c|c|c|c|c|}
\multicolumn{1}{c|}{} & \multicolumn{5}{c|}{ Intensidade de } \\
\cline { 2 - 6 } \multicolumn{1}{c|}{ Relação dos Stakeholders } & $\mathbf{1}$ & $\mathbf{2}$ & $\mathbf{3}$ & $\mathbf{4}$ & $\mathbf{5}$ \\
\hline Sócios & 1 & 1 & 1 & 0 & 3 \\
\hline Famílias & 0 & 1 & 2 & 0 & 6 \\
\hline Funcionários & 1 & 0 & 2 & 2 & 2 \\
\hline Clientes & 0 & 0 & 1 & 0 & 8 \\
\hline Concorrentes & 4 & 1 & 2 & 1 & 1 \\
\hline Fornecedores & 5 & 3 & 0 & 1 & 0 \\
\hline Bancos & 6 & 2 & 1 & 0 & 0 \\
\hline Governo Municipal & 5 & 2 & 2 & 0 & 0 \\
\hline Governo Estadual & 8 & 1 & 0 & 0 & 0 \\
\hline Associação & 4 & 1 & 2 & 2 & 0 \\
\hline Secretaria de Turismo & 3 & 3 & 1 & 2 & 0 \\
\hline Universidades e Faculdades da região & 7 & 1 & 0 & 0 & 1 \\
\hline
\end{tabular}

Fonte: elaboração pelos autores

A Tabela 04 é uma adaptação do modelo de Frooman (1999) onde o autor apresenta uma tipologia dos relacionamentos dos stakeholders versus firma, baseada na teoria de dependência de recursos. Os entrevistados apontam que a empresa é dependente dos stakeholders clientes e a família, enquanto os funcionários e o governo municipal são percebidos como dependentes da empresas. Ao serem questionados quanto à interdependência, os entrevistados identificaram 7 (sete) stakeholders. Os entrevistados 
poderiam responder mais de uma ou em nenhuma opção, dependendo do grau de dependência percebido pela organização.

Tabela 04 - Dependência existente entre a organização e os stakeholders nas pousadas de Urubici - 2006.

\begin{tabular}{|l|c|c|c|}
\hline & $\begin{array}{c}\text { A empresa é } \\
\text { dependente do } \\
\text { stakeholder }\end{array}$ & $\begin{array}{c}\text { O stakeholder } \\
\text { depende da } \\
\text { empresa }\end{array}$ & $\begin{array}{c}\text { Ambos são } \\
\text { interdependentes }\end{array}$ \\
\hline Sócios & 4 & 3 & 2 \\
\hline Famílias & 6 & 5 & 3 \\
\hline Funcionários & 5 & 6 & 0 \\
\hline Clientes & 8 & 1 & 1 \\
\hline Concorrentes & 3 & 4 & 5 \\
\hline Fornecedores & 3 & 2 & 6 \\
\hline Bancos & 1 & 2 & 7 \\
\hline Governo Municipal & 4 & 5 & 2 \\
\hline Governo Estadual & 2 & 1 & 6 \\
\hline Associação Pouserra & 3 & 4 & 5 \\
\hline Secretaria de Turismo & 3 & 4 & 8 \\
\hline Universidades e Faculdades da região & 1 & 0 & \\
\hline
\end{tabular}

Fonte: elaborado pelos autores

Apreciando o exposto por Silva et al. (2005), que os stakeholders são partes do processo de construção a administração do futuro da rede, por serem a ligação entre as organizações, e considerando os resultados da Tabela 04, é possível inferir que as empresas associadas a Pouserra estão em fase inicial do desenvolvimento de uma rede. Os resultados apontam a baixa influência dos concorrentes e da associação, que são atores envolvidos na formação da rede no setor turístico de Urubici. Segundo o exposto por Chisholm (1996), uma das etapas o desenvolvimento da rede é a convocação e participação dos stakeholders. Se para as empresas os concorrentes e a associação têm baixa influência, então a rede talvez não esteja tomando decisões que influenciam as empresas de maneira objetiva e sim apenas decisões que afetam a destinação de forma indireta. No estudo de Sabino et al (2005) também foi possível visualizar a baixa dependência dos concorrentes, entretanto, as pousadas apresentaram alta dependência com as Associações.

\section{CONSIDERAÇÕES FINAIS}

O objetivo geral do trabalho foi analisar os stakeholders e suas influências nas empresas de hospedagem de Urubici/SC. Para isso foram entrevistas todas as pousadas associadas à Pouserra no mês de maio de 2006 e os resultados alcançados com este estudo permitem inferir que a maioria das pousadas são administradas pela família e $50 \%$ abriram o empreendimento quando decidiram mudar de atividade. O número de funcionários é baixo, já que as pousadas são pequenas e possuem gestão familiar, e apenas 3(três) possuem mais de dois funcionários direto. 
O estudo apresenta que os clientes são os stakeholders que mais influenciam as pousadas pertencentes à rede de empresas e em segundo lugar está a família. Os turistas do estado de São Paulo representam $90 \%$ dos clientes. Os casais sem fillhos representam $82 \%$ da clientela das pousadas e a faixa etária é entre 26 a 40 anos. É possível perceber que as empresas pesquisadas demonstram atenção e buscam conhecer quem são seus stakeholders, corroborando com a referência de Silva et al.(2005).

No momento da tomada de decisão, pode-se notar que todos os stakeholders têm possibilidades de participar e que $50 \%$ das entrevistas mostraram que o objetivo de cada ação desenvolvida pelos proprietários da organização é o crescimento desta. Pode-se verificar que os dados apresentados, em alguns fatores, são similares e em outros contrários aos apresentados na pesquisa de Sabino et al (2005), não sendo possível verificar uma padronização quanto à importância e influência dos stakeholders para os atores de uma rede, à exceção dos clientes.

Parece cabível ressaltar que os resultados apresentados na pesquisa podem indicar o desenvolvimento de uma rede de empresas em fase inicial, pois foi identificada o envolvimento de alguns stakeholders nas empresas associadas a Pouserra. Segundo a literatura consultada, o envolvimento e conjunção de vários atores no desenvolvimento e planejamento dos empreendimentos e das atividades turísticas são fatores importantes para a evolução das redes (ENDRES, 2003). Para que uma rede de empresas turísticas contemple seus objetivos, considera-se como ingrediente fundamental a colaboração de todos os agenteschaves da destinação (ALMEIDA, 2000).

Os resultados alcançados ficaram limitados face a recente formação da associação, no período da pesquisa. Acredita-se que há um potencial maior a ser desenvolvido e explorado, gerando contribuições para a competitividade do turismo na destinação de Urubici. Para possibilitar uma análise mais profunda da influência dos stakeholders nas redes de empresas, sugere-se que sejam desenvolvidos estudos futuros acompanhando a estruturação da Pouserra, com um corte longitudinal, bem como, em outras redes de empresas do mesmo setor e de setores diferentes, possibilitando assim uma discussão mais abrangente.

\section{REFERÊNCIAS}

ALMEIDA, E. C. A Busca de Novos Modelos Institucionais e de Planejamento para Promover o Desenvolvimento Sustentável nas Cidades Médias da Bahia num Ambiente de Acirrada Competição: o caso do Senhor do Bonfim. Dissertação de Mestrado para obtenção do grau de mestre em Administração. Universidade Federal da Bahia, Salvador, 2000 .

AMATO NETO, J. Redes de cooperação produtiva e cluster regionais: oportunidades para as pequenas e médias empresas. São Paulo: Atlas, 2000.

Redes dinâmicas de cooperação e organizações virtuais. In Redes entre Organizações. p. 68-93, São Paulo: Atlas, 2005

ANDION, C. Análise de Redes e Desenvolvimento Local Sustentável. Revista de Administração Pública, vol. 37, n.5, p. 1033-54, set-out $2003 a$.

ANDION, C. O papel das Redes na Promoção do Desenvolvimento Local Sustentável. Revista de Saberes (CETEAD/CIRIEC), n.0, p. 51-76, $2003 \mathrm{~b}$. 
ATKINSON, A. J.; WATERHOUSE, J. H.; WELLS, R. B. A stakeholder approach to strategic performance measurement. Sloan Management Review, Spring, v. 38, n. 3, p. 2537, 1997.

BOWDITCH, J .I., BUONO, A. F. Elementos de Comportamento Organizacional. São Paulo: Pioneira, 1992.

CÂNDIDO, G.A.; ABREU, A. F. Os conceitos de redes e as relações interorganizacionais: um estudo exploratório. Anais do $24^{\circ}$ ENANPAD - Encontro Anual da ANPAD; 2000; $24^{\circ}$ ENANPAD - Encontro Anual da ANPAD; Florianópolis; BRASIL; Português; Meio magnético;

CASAROTTO FILHO, N.; PIRES, L. H. Redes de pequenas e médias empresas e desenvolvimento local: estratégias para a conquista da competitividade global com base na experiência italiana. São Paulo: Atlas, 1999.

CHISHOLM, R. F. On the meaning of networks. Group e Organization Management. v. 21, n. 2, jun 1996. p. 216-235.

DONALDSON, T.; PRESTON, L. E. The stakeholder theory of the corporation: Concepts, Evidences and Implications. In Academy of Management Review, v. 20, n. 1, 1995.

ENDRES, A. V. Redes Políticas como Novo Instrumento de Condução Política do Estado: contextualização frente à complexidade social e possibilidade para o planejamento turístico. Turismo Visão e Ação, vol. 5, n. ${ }^{\circ}$ 3, p. 217-238, set/dez 2003.

FLEURY, A.; FLEURY, M. T. L. Desenvolver competências e gerir conhecimentos em diferentes arranjos empresariais. In Fleury, M. T. L., Oliveira Jr., M. M. (org). Gestão Estratégica do Conhecimento: Integrando Aprendizagem, Conhecimento e Competências, Ed. Atlas, 2001.

FREEMAN, R. E.; REED, D. L. Stockholders and Stakeholders: A New Perspective on Corporate Governance. California Management Review, 25. Jg., H. 3, 1983, S. 88-106, 1983.

FREEMAN, E. Strategc Mnagement. In A Stakeholder Approach. London: Pitman Publishing, 1984.

FROOMAN, J. Stakeholder influence strategies. Academy of Managemnent Review, vol. 24, n2, April 1999.

GARCIA, R. C. Vantagens competitivas de empresas em aglomerações industriais: um estudo aplicado à indústria brasileira de calçados e sua inserção nas cadeias produtivas globais. Tese (Doutorado) - Instituto de Economia, Universidade Estadual de Campinas, Campinas, 2001.

HALL, C. M. Planejamento Turístico: políticas, processos e relacionamentos. São Paulo: Contexto, 2001.

HATTON, M. Redefining the relationships - the future of travel agencies and the global agency contract in a changing distribution system. Journal of Vacation Marketing, v.10, n.2, $\operatorname{mar} / 2004$.

HAYES, B. E. Medindo a satisfação do cliente. Rio de Janeiro: Qualitymark , 2001.

HOFFMANN, V. E. Los Factores Competitivos de la Empresa a Partir de la Perspectiva de los Distritos Industriales: uno estudo de la industria de cerámica de revestimiento brasileña. España, 2002. Tesis Doctoral, Universidad de Zaragoza. 
Trabalho de conclusão de disciplina, 2003.

IBGE. Economia do Turismo: análise das atividades características do turismo 2003, Rio de Janeiro: 2007.

JARILLO, J. C. On Strategic Networks. Strategic Management Journal, vol. 9, p. 31-41, 1988.

KARPOUZAS, A.; SANTOS, J. W. O Processo de Formação de Estratégias de uma Organização do Terceiro Setor: análise da influência dos stakeholders a partir de um estudo de caso. Disponível em http://integracao.fgvsp.br/ano8/08/administrando.htm. Acessado em 11 de agosto de 2006.

LAGEMANN, L. Fatores que Influenciam a Performance de Redes de Pequenas e Médias Empresas. Dissertação Administração da Universidade Federal do Rio Grande do Sul, 2004.

MALHOTRA, N. Pesquisa de Marketing: uma orientação aplicada. $3^{a}$ ed., Porto Alegre: Bookman, 2001.

MATTAR, F. N. Pesquisa de marketing. São Paulo: Atlas, 2001, p. 131.

MAZZALI, L.; COSTA, V. M. H. M. As formas de organização "em rede": configurações e instrumento de análise da dinâmica industrial recente. Revista de Economia Política, vol. 17, $\mathrm{n}^{\circ} 4$ (68), outubro-dezembro, 1997.

MILES, R. E.; SNOW, C. C. Network organizations: new concepts for new forms. In California Management Review, California, vol. 23, n. 3, p. 62 - 73, spring 1986.

MITCHELL, R. K.; AGLE, B. R.; WOOD, D. J. Toward a theory of stakeholder indentification and salience: defining the principle of who and really counts. Academy of Management Review, vol. 22, n. 4, p. 853-886, 1997.

PAVLOVICH, Kathryn. The Evolution and Transformation of a Tourism Destination Network: the Waitomo Caves, New Zealand. Tourism Management, vol. 24, p. 203-216, 2003.

PINTO, M. S. L.; OLIVEIRA, R. R. Estratégias competitivas no setor elétrico brasileiro: uma análise dos interesses e expectativas dos atores da CHESF. Revista de Administração Contemporânea - RAC, Anpad, Edição Especial, p. 131-135, 2004.

PORTER, M. E. Competição = On Competition: estratégias competitivas essenciais. $5^{\text {a }}$. Ed. Rio de Janeiro: Campus, 1999.

PUGA, F. P. Alternativas de Apoio a MPMES Localizadas em Arranjos Produtivos Locais. Rio de Janeiro, junho, 2003.

RIBAULT, J. M.; MARTINET, B.; LEBIDOIS, D. A Gestão das Tecnologias. Lisboa: Dom Quixote, 1995.

RICHARDSON, R. J. Pesquisa social: métodos e técnicas. São Paulo: Atlas, 1999.

RICHINS, H. Influences on local government tourism decision-making: (...). The Journal of Tourism Studies, v.11, n.2, dez/2000. 
SABINO, S. S.; HOFFMANN, R. A; HOFFMANN, V. E. A importância dos stakeholders na tomada de decisão das pousadas de Bombinhas. Revista Turismo Visão e Ação. Vol 7 -n.2 p.341-354, 2005.

SANTUR. Perfil da Demanda Turística de Santa Catarina 2005. Disponível em www.santur.sc.gov.br. Acessado em 05 de março de 2006.

SAVAGE, G. T.; NIX, T. H.; WHITEHEAD, C. J.; BLAIR, J. D. Strategies for assessing and managing organizational stakeholders. Academy of Management Executive, vol. 5, n. 2, p. 61-75, 1991.

SELIN, S.; BEASON, K. Interorganizational Relations in Tourism. Annals of Tourism Research, vol. 18, p. 639-652, 1991.

SILVA, C. M. M.; SCHROEDER, L.; HOFFMANN, V. E. As relações interorganizacionais como mecanismo de desenvolvimento. Disponível em: http://www.fae.edu/publicacoes/pdf/art cie/art 09.pdf\#search $=\% 22 \% 22 \mathrm{emil} \% 20 \mathrm{Hoffmann} \%$ 22\%2B $\% 22$ stakeholders $\% 22 \% 22$. Acessado em 15 de agosto de 2006 .

STONER, J. A. F; FREEMAN, R. E. Administração. 5ed. Rio de Janeiro: Pretince Hall do Brasil, 1985.

THORELLI, H. B. Networks: Between markets and hierarchies. Strategic Management Jornal, vol. 7, 1986.

TOMELIN, C. Alberto. Mercado de agências de viagens e turismo: como competir diante das novas tecnologias. São Paulo: Aleph, 2001.

TREMBAY, P. The Economic Organization of Tourim. Annals of Tourism Research, vol. 25, n. 4, p. 837-859, 1998.

VILLELA, L. E. Estratégias de cooperação e competição de organizações em rede - uma realidade pós-fordista?; Congresso; XXIX Encontro Nacional da Associação Nacional de Pós-Graduação e Pesquisa em Administração - EnANPAD; Associação Nacional de PósGraduação e Pesquisa em Administração - ANPAD; Português; Hotel Blue Tree Park; Brasília; BRASIL; Meio digital; www.anpad.org.br; 18 a 21/09/2005. 